\title{
FETAL NEUROSONOGRAPHY AND FETAL BEHAVIOUR
}

\section{FETALNA NEUROSONOGRAFIJA I FETALNA PONAŠANJA}

\author{
Snežana Rakićt,2
}

\section{Summary}

The ultrasonographic monitoring of fetal neural development is one of the most important objectives in perinatal medicine. The aim of this study was to monitor neurological development and analyse fetal behaviour by using $4 \mathrm{D}$ ultrasound. We conducted a prospective study of 150 singleton pregnancies in order to monitor neurological development and analyse fetal behaviour by using $4 \mathrm{D}$ ultrasound. The study was done by using ultrasound machine MEDISON ACCUVIX XQ transvaginal and transabdominal $5 \mathrm{MHz}$ sound with Doppler flow. Fetal movements in the first trimester and fetal facial expressions in the third trimester were analysed. In the first trimester, tests were conducted in the 8th, 12th and 14th week of pregnancy. Embryonic/fetal activity in the first trimester begins with movements that represent the functional expression of early neonatal activity. Identification of first reflexes is a measure of neurological development in the second and third trimester of pregnancy. Development of the central nervous system is a complex process and it is reflected in the complexity of motor, sensory, cognitive and affective functions and patterns of behaviour. Fetal behavioural patterns correlate with the development of central nervous system, while the quality of fetal movements reveals the integrity of central nervous system. For the assessment of fetal brain function a prenatal neurological test (KANET) can be used. 4D ultrasound represents an important advancement in monitoring fetal neurological development and behaviour.

Keywords: central nervous system, fetal behaviour, four-dimensional ultrasound, KANET

\section{Sažetak}

Ultrasonografsko praćenje neurološkog razvoja fetusa je jedan od najznačajnijh ciljeva u perinatalnoj medicini. Cilj ovog rada je bio ispitivanje neurološkog razvoja i analiza fetalnih ponašanja korišćenjem $4 \mathrm{D}$ ultrazvuka. Sproveli smo prospektivnu studiju na 150 jednoplodnih trudnoća radi praćenja neurološkog razvoja i analize fetalnih ponašanja korišćenjem $4 D$ ultrazvuka.Ispitivanje je rađeno upotrebom ultrazvučnog aparata Medison ACCUVIX XQ transvaginalnom i transabdominalnom sondom snage $5 \mathrm{MHz}$ sa Dopler protokom. Analizirani su fetalni pokreti u prvom trimestru i ekspresija fetalnog lica u trećem trimestru. U prvom trimestru ispitivanja su vršena u osmoj, dvanestoj i četrnestoj nedelji trudnoće.Embrionalna/ fetalna aktivnost u prvom trimestru trudnoće počinje pokretima koji predstavljaju funkcionalnu ekspresiju rane neonatalne aktivnosti. Prepoznavanje prvih refleksa je mera neurološkog razvoja u II i III trimestru trudnoće.Razvoj centralnog nervnog sistema je kompleksan proces i odražava se u kompleksnosti motornih, osetnih, kognitivnih i afektivnih funkcija i obrazaca ponašanja. Obrazci fetalnog ponašanja koreliraju sa razvojem centralnog nervnog sistema a kvalitet fetalnih pokreta otkriva integritet centralnog nervnog sistema.Za procenu funkcije fetalnog mozga može se koristi prenatalni neurološki test (KANET). 4D ultrazvuk predstavlja značajan napredak u praćenju fetalnog neurološkog razvoja i ponašanja.

Ključne reči: centralni nervni sistem, fetalno ponašanje, 4 D ultrazvuk, KANET

\section{UvoD}

Ultrasonografsko praćenje neurološkog razvoja fetusa je jedan od najznačajnijih ciljeva u perinatalnoj medicini.Fetalno ponašanje predstavlja fetalnu aktivnost detektovanu ultrazvučnim pregledom. Analiza fetalnog ponašanja doprinosi proceni neurološkog razvoja fetusa. Za ispitivanje morfološkog razvoja embriona i fetusa kao i fetalnih ponašanja najveći značaj ima primena $3 \mathrm{D}$ i 4D ultrazvuka (1). Spontana fetalna aktivnost u preterminskih i terminskih fetusa bi mogla biti indikator fetalne disfunkcije u ranim fazama fetalnog razvoja. Kardinalni pokreti fetusa su najčešći i najkompleksniji pokreti i oni su mera fetalne neurološke maturacije (2). U više izvedenih studija ispitivani su razvoj fetalnih pokreta i neurološki razvoj (3). Fetalno ponašanje predstavlja fetalnu aktivnost detektovanu ultrazvučnim pregledom. Analiza fetalnih ponašanja doprinosi proceni normalnog i patološkog neurološkog fetalnog razvoja. Uvođenje 3D i 4D ultrazvučne tehnologije omogućila je bolju vizuelizaciju fetalne anatomije i fetalnog ponaša- nja in utero (4). Sa napredovanjem gestacijske starosti trudnoće fetalni kvantitativni i kvalitativni obrasci ponašanja postaju sve složeniji. Sporadični pokreti tela fetusa se menjaju u dobro organizovane obrasce ponašanja (5). Iako danas postoje savremene visokotehnološki razvijene ultrasonografske tehnike, nije uvek moguće direktno analizirati funkcionalni razvoj fetalnog nervnog sistema.

\section{Cilj RAda}

Cilj tada je bio procena neurološkog razvoja embriona i fetusa na osnovu praćenja njihovog morfološkog razvoja i analize fetalnih ponašanja.

\section{MATERIJAL i METODE}

Ispitivanje predstavlja prospektivnu studiju sprovedenu na 150 trudnica sa jednoplodnom trudnoćom, radi pra- 
ćenja neurološkog razvoja i analize fetalnih ponašanja. Ispitivanje je vršeno korišćenjem 2D i 4D ultrazvuka. 4D ultrazvučno ispitivanje je rađeno na ultrazvučnom aparatu Medison ACCUVIX XQ, transvaginalnom i transabdominalnom sondom snage $5 \mathrm{MHz}$ sa Dopler protokom. Transvaginalni 4D kolor Doppler ultrazvuk smo koristi osim za ispitivanje morfologije embriona i fetusa i za funkcionalno hemodinamsko ispitivanje fetalnog cerebrospinalnog krvnog protoka u prvom trimestru. Posle 10 nedelje trudnoće koristili smo transabdominalni $4 \mathrm{D}$ ultrazvuk zbog veće mogućnosti ispitivanja fetalnih pokreta. Analizirani su fetalni pokreti u prvom trimestru trudnoće i fetalna ponašanja u II i III trimestru trudnoće. Vreme pregleda je bilo između 12 i $17.30 \mathrm{~h}$ bez uzimanja obroka hrane $2 \mathrm{~h}$ pre ispitivanja. U prvom trimetstru ispitivanja su vršena u 8 , 12 i 14 nedelji trudnoće. Za analizu fetalnih ponašanja u II i III trimestru trudnoće ispitivane trudnice su bile podeljene u grupu trudnoća niskog rizika (77 trudnica) i grupu trudnoća visokog rizika (73 trudnice). Grupu trudnoća visokog rizika sačinjavalo je 30 trudnica sa preterminskom prevremenom rupturom plodovij ovojaka, 11 trudnica sa postterminskom trudnoćom i 32 trudnice sa gestacijskim dijabetes melitusom. Za procenu stanja fetalnog centralnog nervnog sistema upotrebom 4D ultrazvuka koristili smo Kurjakov antenatalni neurološki test (Kurjak Antenatal Neurodevelopmental Test) - KANET iz 2008 godine (6). Ovaj test smo izvodili u trećem trimestru trudnoće između 28 i 38 nedelje trudnoće. Ispitivanje ovim testom traje oko 20 minuta. Parametri KANET testa su: izolovana antefleksija glave, kranijalne suture, cirkumferencija glave, izolovano treptanje oka, promene lica, otvaranje usana, izolovani pokreti ruke, izolovani pokreti noge, položaj palca, Gestelt percepcija o fetalnim generalizovanim pokretima. Svaki pojedinačni fetalni parametar i znak se boduju. Normalni fetusi imaju KANET skor između 14-20, što predstavlja skor optimalnog neurološkog razvoja. Fetusi sa potencijalnim neurološkim abnormalnostima imaju skor od 5-13. Fetusi koji su neurološki abnormalni imaju prenatalni skor od 0-5. U slučaju postojanja neurološki abnormalnog testa, on se ponavlja svake dve nedelje do porođaja. Dobijeni podaci su statistički obrađeni korišćenjem metoda analitičke statistike: studentov t-test i X $\mathrm{X}^{2}$ test.

\section{REZULTATI}

U našem ispitivanju detekcija trudnoće $2 \mathrm{D}$ ultrazvukom u 3-4 nedelji trudnoće zasnivala se na opažanju: decidualne reakcije, intradecidualnog znaka, i postimplantacionog krvavljenja. U 5 nedelji trudnoće bio je vidljiv gestacioni mešak, a žumačna kesa je bila vidljiva kao znak duplog prstena.U 5,5 nedelji trudnoće detektuje se embrion sa srčanom radnjom. U 7-9 nedelji vidljiv je embrion, centralni nervni sistem i amnionske membrane.2D ultrazvukom je u 7. nedelji merena duži- na embriona tj rastojanje teme-trtica (TT) koje je iznosi lo oko $12 \mathrm{~mm}$,vizuelizuje se fetalna glava i neuralna cev. U 8 nedelji dužina ploda je dužine $15 \mathrm{~mm}$, vizuelizuje se centralni nervni sistem sa svojim elemenatima i to: rombencefalon, prozencefalon i mezencefalon. Duž stražnje strane embriona moguće je videti osifikacione tačke-jedra medule spinalis tj neuralne cevi. U 10 nedelji trudnoće bile su vidljive bočne komore sa pleksus horoideusom i falks cerebri (Butterfly znak). U 12 nedelji vidljiva je medula spinalis, bočne komore, falks cerebri i cerebelum. Izgled fetusa u 13. nedelji trudnoće posmatran 4D ultrazvukom prikazan je na slici 1.

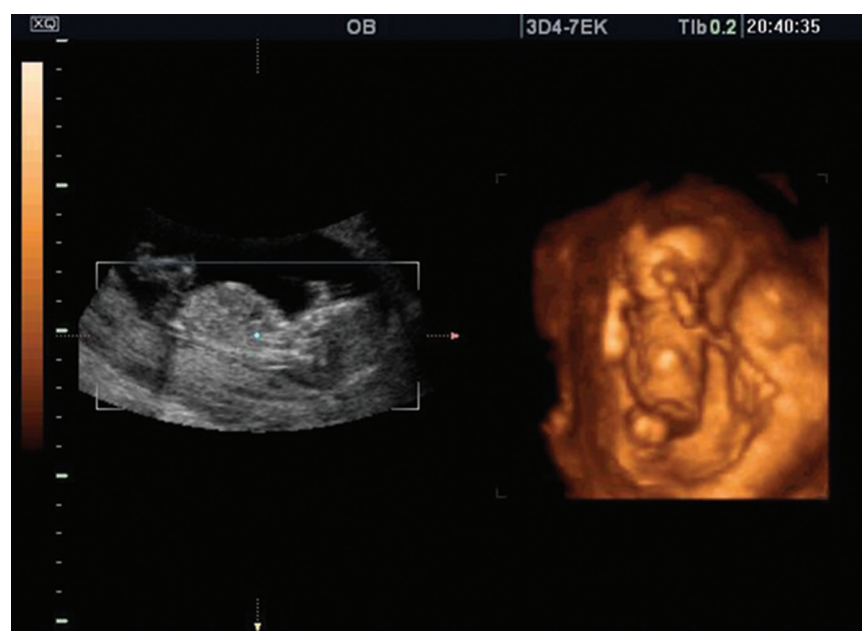

Slika 1. Fetus u 13 nedelji trudnoće, 4D ultrazvuk

Distribucija embrionalnih i fetalnih pokreta u I trimestru trudnoće u našem ispitivanju prikazana je na tabeli br 1.

Prepoznavanje prvih refleksa je mera neurološkog razvoja u drugom i trećem trimestru trudnoće od kojih su refleks hvatanja i mogući Moro refleks dva najznačajnija. U 11,4 nedelji trudnoće registrovali smo da fetus hvata pupčanu vrpcu, ako ona dođe na palmarnu stranu šake, to je palmarni refleks hvatanja pupčane vrpce. Ovo smo videli kod $>95 \%$ fetusa pri ispitivanju između 11,2 - 11,5 nedelja trudnoće. Ovaj refleks je trajao oko 4 minuta. Prvi fetalni refleksi prikazani su na slici 2.

Tabela 1. Distribucija pokreta embriona i fetusa u I trimestru trudnoće

\begin{tabular}{lccc} 
Vrsta pokreta & $\begin{array}{c}\text { Gestacijska } \\
\text { starost } \\
\text { trudnoće u } \\
\text { nedeljama }\end{array}$ & $\begin{array}{c}\text { Dužina } \\
\text { trajanja u } \\
\text { sekundama }\end{array}$ & $\begin{array}{c}\text { Viđeni } \\
\text { ultrazvu- } \\
\text { kom \% } \\
\text { fetusa }\end{array}$ \\
\hline Prvi embrionalni pokreti & 7,4 & 2 & 80 \\
\hline Generalizovani pokreti & 8,3 & 5 & 90 \\
Istezanje & 10 & 3 & 82 \\
\hline Štucanje & 9 & 3 & 95 \\
Otvaranje usta & 10,5 & 1,5 & 82 \\
Disajni pokreti & 10,5 & 5 & 92 \\
Pokreti ruke prema glavi & 10 & 1,5 & 98 \\
Rotacija glave & 10 & 2 & 98 \\
Gutanje & 12 & 1 & 94,3
\end{tabular}




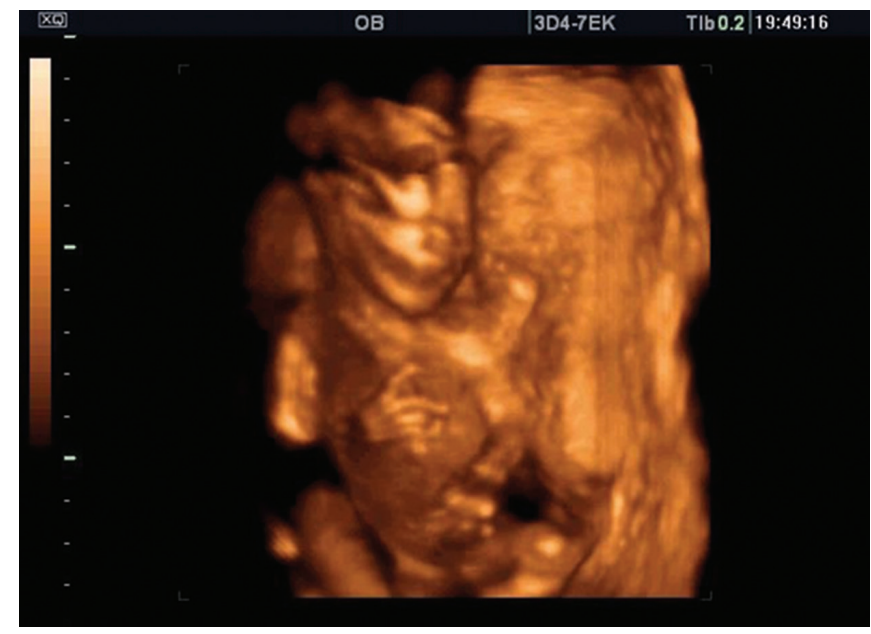

Slika 2. Prvi fetalni refleksi, 4D ultrazvuk

FETALNO PONAŠANJE U DRUGOM I TREĆEM TRIMESTRU TRUDNOĆE

Kada su u pitanju fetalna ponašanja u II trimestru u našem uzorku diferenciraju se dve grupe pokreta: veliki pokreti gornjih ekstremiteta kao i facijalne ekspresije. Pokret otvaranja očiju fetusa smo detektovali najranije u 20 nedelji gestacije. U 34 nedellji trudnoće registrovali smo brze ili spore pokrete očiju fetusa. Za ova ispitivanja su bila neophodna 4D ultrazvučna ispitivanja jer se njima obezbeđuje kvantitet i kvalitet pokreta fetalne facijalne ekspresije.

U trećem trimestru održava se refleks hvatanja, a analiziraju se pokreti gornjih ekstremiteta prema glavi, pokreti šaka prema glavi, ustima, oku, licu i uhu, pokreti glave ( izolovana retrofleksija glave i izolovana rotacija glave), kao i izraz lica (izolovano žmirkanje, zatvaranje i otvaranje očiju, zevanje, plaženje jezika, pućenje usta, sisanje i gutanje). Postoji longitudinalno smanjenje incidence ovih pokreta kako gestacija napreduje kao i njihovo ciklično smenjivanje u periodu od 36-40 nedelje trudnoće. Ponašanje fetusa u III trimestru prikazano je na slici 3.

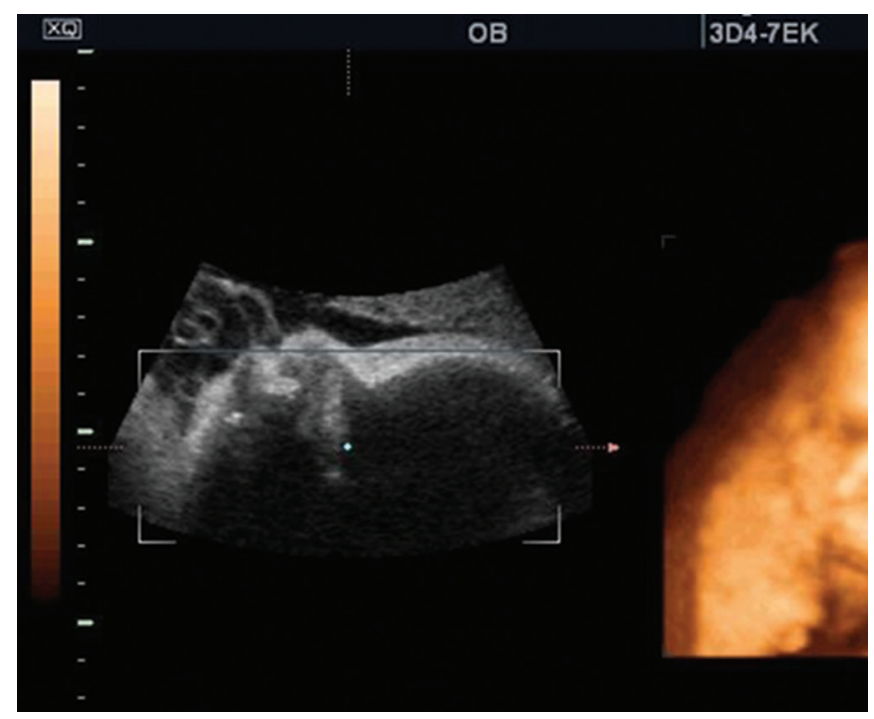

Slika 3. Ponašanje fetusa u III trimestru, 4D ultrazvuk
U grupi trudnica sa 40+6 nedelja trudnoće nađena je veća incidenca pokreta zevanja fetusa nego u grupi trudnica od 37- 40 nedelja trudnoće, $\mathrm{p}<0.05$. Pokreti zevanja nisu do sada kompletno objašnjeni. Oni su pokrenuti aktivnošću nižih delova mozga u cilju eliminacije prolazne hipoksije fetalnog nervnog sistema.Za procenu integriteta centralnog nervnog sistema fetusa upotrebom 4D ultrazvuka koristili smo Kurjakov antenatalni neurološki test - KANET.

\section{KANET test kod trudnica sa gestacijskim dijabetes} melitusom

Naša studija je obuhvatala 32 trudnice sa gestacijskim diabetes melitusom. U $19(69,37 \%)$ od njih postojale su razlike jednog od ispitivanih parametara KANET skora koje su bile značajno različite i one su nađene za izolovanu retrofleksiju glave, izolovano treptanje oka, izraz lica, pokrete usana, izolovane pokrete ruke i za generalizovane pokrete. Za izolovane pokrete noge i za kranijalne suture razlike nisu bile značajne. KANET skor u ovoj grupi je bio od 8-11. ATNAT test je primenljiv za ovu grupu do dve godine starosti.

KANET test kod trudnica sa preterminskom prevremenom rupturom plodovih ovojaka

Naše ispitivanje je obuhvatilo 30 trudnicu sa preterminskom prevremenom rupturom plodovih ovojaka. Naši rezultati ukazuju da od 25-33 nedelje trudnoće dolazi do smanjenja pokreta glave i izraza lica fetusa.. KANET skor je bio od 6-13. Postoji i redukcija disajnih pokreta i refleksa hvatanja. Dolazi do promena u fetalnoj cerebralnoj cirkulaciji sa porastom protoka na kraju dijastole u a. cerebri medii.

\section{KANET test kod trudnica sa postterminskom trud-} noćom

Naše ispitivanje je obuhvatalo 11 trudnica sa postterminskom trudnoćom.Kod postterminskih trudnoća KANET skor je bio od 7-11, postoji redukcija fetalnih pokreta i velika incidenca fetalnih pokreta sličnih onim kod iritacije centralnog nervnog sistema.

\section{DiskUsija}

Embrionalni i fetalni pokreti predstavljaju osnovnu fundamentalnu ekspresiju ranog neurološkog razvoja. Rani embrionalni razvoj karakteriše nepokretnost embriona (7). Prve spontane pokrete embriona u našem ispitivanju smo registrovali u 7,4 nedelje trudnoćese . Oni se sastoje od spore fleksije i ekstenzije trupa, a praćeni su pasivnim promenama položaja fetalnih ekstremiteta. Generalizovani pokreti celog tela se javljaju kasnije, u 9 nedelji trudnoće (8).U našem ispitivanju ispitivanju generalizovane pokrete smo registrovali u 8,3 nedelje trudnoće. Pokrete ruke prema glavi fetusa i pokrete rotacije glave fetusa smo registrovali u 10 .nedelji trudnoće. Otvaranje usta i disajne pokrete smo registrovali 
u 10,5 nedelji trudnoće a pokrete gutanja u 12.nedelji trudnoće. Od 10 nedelje trudnoće raste broj i učestalost fetalnih pokreta (2). Kompleksni pokreti se pojavljuju u 10-12 nedelji trudnoće. U 11-12 nedelji trudnoće javljaju se izolovani pokreti ruku i nogu.U 14 nedelji trudnoće su češći i organizovaniji pokreti nego u 12 nedelji trudnoće (9). Razvoj vegetativnog nervnog sistema se evidentira u embrionalnoj srčanoj radnji u 5,5 nedelji trudnoće a potom i kroz evidenciju pokreta gutanja, štucanja, disajnih pokreta i dr. Glavna karakteristika druge polovine trudnoće je organizacija fetalnih pokreta. Poslednjih 10 nedelja trudnoće smanjuje se broj krupnih pokreta tela, a dolazi do porasta broja pokreta lica (10). Pokreti očiju se mogu pratiti u III trimestru. Oni se pojavljuju između 16-18 nedelje trudnoće u vidu pojedinačnih pokreta. U 22 nedelji trudnoće primećuje se otvaranje očiju a u 33 nedelji mogu se razlikovati brzi i spori pokreti očiju (11). Prepoznavanje prvih refleksa je mera neurološkog razvoja u drugom i trećem trimestru trudnoće od kojih su refleks hvatanja i Moro refleks dva najznačajnija. Palmarni refleks hvatanja pupčanika smo detektovali u preko 95\% ispitivanih fetusa. Ovaj refleks je prisutan na rođenju i traje u prva 3 meseca života. Sumnjivo je ako ovaj refleks postoji i posle 3 meseca života, a nenormalno je ako se održava i posle 6 meseci. On je zavisan od motornog dela korteksa (12). Moro refleks se razvija u 9. nedelji trudnoće a potpuno je razvijen oko 34 . nedelje trudnoće. Fetus pomera ruke napred i u stranu sa ekstenzijom podlaktica i šaka. On je prisutan na rođenju i perzistira 4-6 meseci. Njegovo odsustvo u prvih nekoliko meseci je nađeno kod teških cerebralnih oštećenja. Pokreti zevanja fetusa u našem ispitivanju u grupi trudnica sa $40+6$ nedelja trudnoće su bili značajno učestaliji nego u grupi trudnica od 37-40 nedelje trudnoće, $p<0.05$. Pokreti zevanja nisu do sada kompletno objašnjeni. Ovi pokreti su pokrenuti aktivnošću nižih delova mozga u cilju eliminacije prolazne hipoksije fetalnog nervnog sistema. Procena fetalnog ponašanja za vreme različitih perioda gestacije mogla bi poslužiti za razlikovanje između normalnog i abnormalnog razvoja mozga (6). Zagrebačka grupa je 2008 godine napravila test za procenu integriteta fetalnog centralnog nervnog sistema upotrebom 4D ultrazvuka. To je Kurjakov antenatalni neurološki test - KANET. Ovaj test je standardizovan u Osaki u Japanu 2010 godine. KANET se izvodi u trećem trimestru trudnoće između 28 i 38 nedelje trudnoće. Ispitivanje ovim testom traje do 30 minuta . Normalni fetusi imaju KANET skor između 14-20, što predstavlja skor optimalnog neurološkog razvoja. Fetusi sa potencijalnim neurološkim abnormalnostima imaju skor od 5-13. Fetusi koji su neurološki abnormalni imaju prenatalni skor od 0-5 (13). U našem ispitivanju KANET testom kod trudnica sa gestacijskim dijabetes me- litusom vrednosti KANET skora su bile od 8-11, u grupi trudnica sa preterminskkom prevremenom rupturom plodovih ovojaka KANET skor je bio od 6-13, a u grupi trudnica sa postterminskom trudnoćom vrednosti KANET skora su bile od 7-11. Za procenu neurološkog statusa novorođenčeta koristi se neonatalni neurološki test Amiel-Tison sa upotrebom 4D ultrazvuka, ATNATAmiel Tison Neurological Assessment at Term (14). Test se zasniva na saznanju o neurološkoj maturaciji delova centralnog nervnog sistema. Dva sistema kontrolišu motoriku fetusa i novorođenčeta. Donji sistem (produžena moždina i mali mozak) održava posturalnu kontrolu protiv sile teže i kontrolu mišića fleksora ekstremiteta. Klinički se procenjuje od 28 nedelje trudnoće. Gornji sistem (moždane hemisfere i bazalne ganglije) kontroliše donji sistem uz relaksaciju ekstremiteta. Klinički se procenjuje od 34 nedelje trudnoće (10). Ako su vrednosti testa granične ili abnormalne, onda se posmatarju veliki pokreti do 46 nedelje od menstruacije ili do pojave neurološkog ispada u prve dve godine života.

\section{ZAKLJUČAK}

Ultrasonografske tehnike a posebno 4D ultrazvuk omogućuju praćenje fetalnog neurološkog razvoja i fetalnih ponašanja. Naša studija je pokazala da se nakon generalizovanih pokreta u I trimestru javljaju izolovani pokreti ekstremiteta, čija incidenca raste do 14. nedelje trudnoće. Prvi znak razvoja vegetativnog nervnog sistema je evidencija srčane radnje u 5,5 nedelji gestacije. Prvi motorni refleks je refleks hvatanja u 11,4 nedelji trudnoće, čija incidenca postepeno opada u II i III trimestru. Faze mira i aktivnosti su siklične u odnosu 1:2. Upotrebom $4 \mathrm{D}$ ultrazvuka i određivanjem vrednosti KANET skora može se proceniti integritet centralnog nervnog sistema fetusa.Vrednosti KANET skora u grupi trudnica sa gestacijskim dijabetesom, preterminskim prevremenim prsnućem plodovih ovojaka i postterminskom trudnoćom u našem ispitivanju ukazuju da su to fetusi sa potencijalnim neurološkim abnormalnostima.U perspektivi će poseban značaj imati istraživanja fetalne cerebralne cirkulacije i fetalnih facijalnih ekspresija u drugom i trećem trimestru trudnoće.

\section{NAPOMENA}

Rad je usmeno izložen na mini simpozijumu Aktuelna dostignuća u savremenoj ginekologiji i akušerstvu na 44. simpozijumu Stremljenja i novine u medicini, Medicinski fakultet u Beogradu, 10.12.2015. godine.

\section{Literatura}

1. Kurjak A, Pooh RK, Merce LT, Carrera JM, Salihagic-Kadic A, Andonotopo W. Structural and functional early human development assessed by three-dimensional and four-dimensional sonography. Fertil Steril 2005; 84: 1285-99.
2. Hata T, Kanenishi K, Sasaki M. Four-dimensional sonographic assessment of fetal movement in the late first trimester. Int J Gynecol Obstet 2010;109:190-3. 
3. Prechtl HFR, Einspieler C. Is neurological assessment of the fetus possible?Eur J Obstet Gynecol Reprod Biol 1997; 75:81-4.

4. Merz E, Abramowicz JS. 3D/4D ultrasound in prenatal diagnosis, as it time for routine use? Clin Obstet Gynecol 2012; 55: 336-51.

5. de Vries JIP, Visser GHA, Prechtl HFR. The emergence of fetal behavior II. Quantitative aspects. Early Human Dev 1985; 12: 99-120.

6. Kurjak A, Miskovic B, Stanojevic M, Amiel-Tison C, Ahmed B, Azumendi G, et al. New scoring system for fetal neurobechavior assessed by three and four dimensional sonography. J Perinat Med 2008; 36: 73 81.

7. Prechtl HFR.Ultrasound studies of human fetal behaviour.Early Hum Dev 1985;12:91-8.

8. de Vries JIP, Fong BF. Normal fetal motility. An overview. Ultrasound Obstet Gynecol 2006; 27:701-11.

9. Kurjak A, Azumendi G, Vecek N, Kupesic S, Solak M, Varga D, et al. Fetal hand movements and facial expression in normal pregnancy studied by four-dimensional sonography. J Perinat Med 2003; 3: 496508
10. Amiel-Tison C, Gosselin J, Kurjak A. Neurosonography in the second half of fetal life: a neonatologists point of view. J Perinat Med 2006;34:437-46.

11. Petrikovsky B, Kaplan G, Helsten N. Eyelid movements in normal human fetuses. J Clin Ultrasound 2003;31:299-301.

12. Sherer DM. Fetal grasping at 16 weeks gestation. J Ultrasound Med 1993; 12: $316-21$.

13. Kurjak A, Luetic AT. Fetal neurobehavior assessed by three-dimensional / four dimensional sonography. Zdrav Vestn 2010;79:790-9.

14. Antakslis P, Kurjak A, Izetbegovic S. Functional test for fetal brain the role of KANET test. Donald School J Ultrasound Obstet Gynecol 2013;7:385-99. 